\title{
Épocas de colheita e qualidade fisiológica de sementes de crambe
}

\section{Harvest seasons and physiological quality of crambe seeds}

\author{
Marina Borges de Oliveira ${ }^{1 *}$; Andréia Márcia Santos de Souza David²; \\ Hugo Tiago Ribeiro Amaro ${ }^{3}$; Miquéias de Oliveira Assis ${ }^{4}$; \\ Bruno Rafael Alves Rodrigues ${ }^{5}$; Ignacio Aspiazú ${ }^{2}$; Abner José de Carvalho ${ }^{2}$
}

\section{Resumo}

Objetivou-se com esse trabalho avaliar as diferentes épocas de colheita sobre a qualidade fisiológica de sementes de crambe, cultivar FMS Brilhante. O experimento foi instalado na Área Experimental da Universidade Estadual de Montes Claros - UNIMONTES, em Janaúba, MG, em 03 de setembro de 2011. A primeira colheita dos racemos foi realizada aos 14 dias após a floração, quando aproximadamente $50 \%$ das plantas apresentavam floração plena. As demais colheitas foram realizadas em intervalos de seis em seis dias, perfazendo um total de cinco colheitas. Foi determinado também o acúmulo de unidades térmicas, em graus dia, durante os intervalos de tempo. Os racemos colhidos foram levados ao Laboratório de Análise de Sementes da UNIMONTES, onde permaneceram sob condições ambientais até a realização das análises. As sementes foram avaliadas quanto ao teor de água, à germinação e ao vigor (matéria seca de sementes, massa de mil sementes, emergência de plântulas e índice de velocidade de emergência). O delineamento experimental utilizado foi inteiramente casualizado, com cinco épocas de colheita, que consistiram nos tratamentos, e quatro repetições. As sementes de crambe apresentam dormência pós-colheita. O máximo acúmulo de matéria seca (maturidade fisiológica) ocorreu aos 26 dias após a floração. Conclui-se que a melhor época para realizar a colheita de sementes de crambe, cultivar FMS Brilhante, com maior qualidade fisiológica (máximo de germinação e vigor) ocorre no período de 14 a 26 dias após a floração, que representa uma soma térmica de 1111,1 a 1302,15 graus dia. Palavras-chave: Crambe Abssinica Hochst, germinação, maturidade fisiológica, vigor

\begin{abstract}
The objective of this study was to evaluate different harvest seasons on the seed quality of crambe, cultivar FMS Brilhante. The experiment was carried out at Experimental area of the Montes Claros State University - UNIMONTES in Janaúba-MG, on September 3, 2011. The first raceme harvest was performed 14 days after flowering, when approximately $50 \%$ of the plants showed full flowering. The other harvests were performed every six days, making a total of five harvests. Accumulation of thermal units in degrees day during time intervals was also determined. The collected racemes were taken to the Laboratory of Seed Analysis at UNIMONTES, when they remained under ambient conditions until beginning the analyses. Seeds were evaluated as for water content, germination and vigor (dry

1 Enga Agra , Discente do Curso de Mestrado em Produção Vegetal no Semiárido, Universidade Estadual de Montes Claros, UNIMONTES, Campus Janaúba, MG. E-mail: mariunim@yahoo.com.br

2 Profs. do Dept ${ }^{\circ}$ de Ciências Agrárias, UNIMONTES, Campus Janaúba, MG. E-mail: andreia.david@unimontes.br; aspiazu@ gmail.com; abjocar@yahoo.com.br

3 Eng ${ }^{\mathrm{o}}$ Agr $^{\mathrm{o}}$, Discente do Curso de Doutorado em Fitotecnia, Universidade Federal de Viçosa, UFV, Viçosa, MG. E-mail: htiagoamaro@yahoo.com.br

4 Eng $^{\circ}$ Agr $^{\circ}$, Discente do Curso de Mestrado em Fitotecnia, Universidade Federal de Viçosa, UFV, Viçosa, MG. E-mail: miqueias.

5 Discente do Curso de Graduação em Agronomia, UNIMONTES, Campus Janaúba, MG. E-mail: rafabrunoalves@hotmail.com Autor para correspondência
\end{abstract} assis@ufv.br 
seed weight, thousand seeds weight, seedling emergence, and emergence speed). The experimental design was completely randomized, with five harvest seasons, which composed the treatments, and four replications. Crambe seeds present post-harvest dormancy. The maximum dry matter accumulation (physiological maturity) occurred 26 days after flowering. In conclusion, the best time to harvest crambe seeds, cultivar FMS Brilhante, with higher physiological quality (maximum germination and vigor) occurs within 14 to 26 days after flowering, which is a thermal sum 1111,1 to 1302,15 degree day.

Key words: Crambe Abssinica Hochst, germination, physiological maturity, vigor

A busca constante pela utilização de energias alternativas tornou-se prioridade e o biodiesel obtido principalmente a partir de óleos e gorduras de origem vegetal e animal, na qualidade de combustível limpo e renovável, vem assumindo um crescimento acentuado de sua produção, o que poderá reduzir o uso de combustíveis fósseis.

As principais espécies oleaginosas cultivadas para a produção de biodiesel são algodão, amendoim, canola, crambe, girassol, soja, dendê, mamona e pinhão manso (FARIA JÚNIOR, 2013). O crambe (Crambe abyssinica Hochst), contém cerca de $37 \%$ de óleo em sua semente que é constituído por até $57 \%$ de ácido erúcico. Devido à presença desse ácido, o óleo de crambe não é adequado para alimentação humana, o que é uma vantagem, pois esta cultura fica destinada apenas para fins industriais (CARLSON et al., 2007). Além disso, a cultura apresenta tolerância à seca, à geada depois de estabelecida e elevada precocidade (FUNDAÇÃO MS, 2007).

Apesar do crescente interesse pela cultura, as pesquisas sobre o assunto ainda são incipientes, principalmente quanto à tecnologia de produção de sementes de qualidade. A alta qualidade das sementes é obtida por meio da condução correta dos campos de produção e, especialmente, da realização da colheita no momento adequado, considerando o ponto de maturação fisiológica, pois a permanência das sementes no campo após a maturidade fisiológica pode ser associada a perdas na produtividade, germinação e vigor (SOUSA et al., 2011).

No caso do crambe, a realização da colheita no momento certo é ainda mais importante, uma vez que a maturação afeta diretamente a qualidade fisiológica das sementes, devido esta espécie apresentar hábito de florescimento indeterminado, encontram-se sementes em uma mesma planta em diferentes estádios de maturação. Para estas plantas, o florescimento e, consequentemente, a produção das sementes, ocorrem por um maior período, o que evidencia os efeitos da maturação na qualidade das sementes (OLIVA, 2010).

Face às considerações, o objetivo do trabalho foi avaliar as diferentes épocas de colheita sobre a qualidade fisiológica de sementes de crambe, cultivar FMS Brilhante.

O campo de produção de sementes foi instalado na Área Experimental do Departamento de Ciências Agrárias da Universidade Estadual de Montes Claros (DCA/UNIMONTES), em Janaúba, MG, em 03 de setembro de 2011, cujas coordenadas geográficas

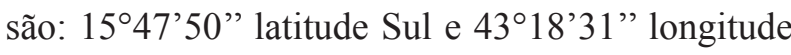
Oeste, a uma altitude de 540 metros.

O clima da região é do tipo "AW" (tropical com inverno seco), com temperatura e precipitação média anual de $25^{\circ} \mathrm{C}$ e $900 \mathrm{~mm}$, respectivamente. $\mathrm{O}$ solo da área experimental é classificado como Latossolo Vermelho eutrófico.

Em uma área de $257 \mathrm{~m}^{2}(11,7 \mathrm{~m}$ x $22 \mathrm{~m})$, foram plantadas sementes de crambe, cultivar FMS Brilhante, safra 2011, provenientes da Cooperativa Agropecuária Pioneira (COOAPI) localizada na região da Chapada Gaúcha, MG. O preparo do solo foi convencional, constando de uma aração e gradagem realizada em pré-plantio. Utilizou-se espaçamento de $0,40 \mathrm{~m}$ entre linhas com semeadura de 20 sementes por metro, a uma profundidade de $3 \mathrm{~cm}$. As sementes foram semeadas em 29 linhas, desprezando-se as plantas que se encontravam a três linhas das extremidades como bordadura. 
A adubação foi baseada nas características químicas do solo na camada de 0 a $20 \mathrm{~cm}$ de profundidade e de acordo as recomendações para a cultura do crambe, que constou da aplicação da formulação 04:14:08 (150 $\left.\mathrm{kg} \mathrm{ha}^{-1}\right)$ no plantio, mais $45 \mathrm{~kg} \mathrm{ha}^{-1}$ de nitrogênio em cobertura, aos 25 dias após o plantio, aplicados via solo em filete contínuo. Após a semeadura, foram adotadas recomendações técnicas necessárias ao desenvolvimento ideal da cultura, incluindo a irrigação em sistema de microaspersão e o controle de plantas daninhas, realizado através de capinas manuais.

Após a emergência das plântulas (09/09/2011) foi realizado o desbaste na cultura deixando em cada linha de plantio 17 plantas por metro, o que representou população final de aproximadamente 425.000 plantas por hectare.

Os racemos foram colhidos de maneira aleatória retirando uma amostra representativa das linhas de plantio, de forma que a quantidade de sementes atendesse à demanda das análises realizadas posteriormente. A primeira época de colheita das sementes $(15 / 11 / 2011)$ foi realizada aos 14 dias após a floração (01/11/2011), considerada quando aproximadamente mais de $50 \%$ das plantas apresentaram floração. As demais colheitas foram realizadas em intervalos de seis em seis dias. Determinou-se o acúmulo de unidades térmicas, em graus dia (GD), durante a condução do experimento.

Após a colheita, os racemos foram levados ao Laboratório de Análise de Sementes do DCA/ UNIMONTES, e em seguida, distribuídos sobre papel, onde permaneceram em condições ambientais $\left(25^{\circ} \mathrm{C}\right)$, até atingirem umidade em torno de $10 \%$. Para avaliação da qualidade fisiológica das sementes foram realizados os seguintes testes:

O teor de água foi determinado conforme metodologia prescrita nas Regras para Análise de Sementes (BRASIL, 2009), utilizando-se o método da estufa, a $105 \pm 3{ }^{\circ} \mathrm{C}$, durante 24 horas, com quatro repetições com cerca de $16 \mathrm{~g}$ por tratamento, sendo os resultados expressos em \% de umidade.
Simultaneamente, foi determinado o peso da matéria seca das sementes, sendo os resultados expressos em mg semente ${ }^{-1}$.

Foi determinada a massa de mil sementes, utilizando-se oito repetições de 100 sementes, as quais foram pesadas em balança de precisão $(0,001 \mathrm{~g})$ e calculados a variância, o desvio padrão e o coeficiente de variação dos valores obtidos nas pesagens, seguindo os critérios estabelecidos nas RAS (BRASIL, 2009), sendo os resultados expressos em gramas.

O teste de germinação foi realizado com quatro repetições de 50 sementes por tratamento, semeadas em caixas tipo gerbox, onde as sementes foram distribuídas sobre uma folha de papel mata-borrão, previamente umedecidas com água destilada, em quantidade equivalente a 2,5 vezes o peso do papel. As sementes foram colocadas em germinador previamente regulado à temperatura constante de 25 ${ }^{\circ} \mathrm{C}$ e luz constante. As avaliações foram realizadas no quarto e sétimo dias após a semeadura, e os resultados expressos em porcentagem, segundo os critérios estabelecidos pela RAS (BRASIL, 2009).

O teste de emergência de plântulas foi conduzido sob condições ambientais de laboratório, e as sementes foram semeadas a uma profundidade de 2 $\mathrm{cm}$ em caixas tipo gerbox contendo como substrato areia lavada e esterilizada com quantidade de água equivalente a $60 \%$ da capacidade de retenção, cuja umidade foi mantida por meio de irrigações diárias (BRASIL, 2009). Foram utilizadas quatro repetições de 50 sementes por tratamento, sendo os resultados obtidos pelo número de plântulas normais emergidas obtidas ao sétimo dia após a instalação do teste.

$O$ índice de velocidade de emergência foi conduzido em conjunto com o teste de emergência de plântulas, anotando-se diariamente, o número de plântulas emergidas, que apresentaram alça cotiledonar acima da superfície do substrato. Ao final do teste, com os dados diários do número de plântulas, foi calculado o índice de velocidade de emergência, empregando-se a fórmula proposta por Maguire (1962). 
O delineamento experimental utilizado foi inteiramente casualizado, composto por cinco épocas de colheitas, que consistiram nos tratamentos, com quatro repetições. Os resultados foram submetidos à análise de variância e regressão em nível de 5\% pelo teste " $F$ ". As estimativas dos parâmetros da regressão foram avaliadas pelo teste " $t$ ” em nível de $5 \%$ de significância.

A determinação do teor de água, como procedimento inicial na avaliação da qualidade fisiológica das sementes de crambe, cultivar FMS Brilhante, indicou que não houve efeito das épocas de colheita sobre a umidade das sementes, sendo obtido um valor médio de 9,5\%. Após a colheita, as sementes de crambe destinadas ao armazenamento e comercialização devem apresentar até $10 \%$ de umidade (KNIGHTS, 2002) devido ao fato desta espécie apresentar, em sua constituição química, grande quantidade de lipídios. Desse modo, o teor de água situou-se dentro do padrão considerado ideal para o armazenamento e comercialização de espécies oleaginosas como o crambe.

As sementes que podem sofrer secagem após a colheita até atingir baixos teores de água, sem a ocorrência de danos ao metabolismo, e recuperarem as funções biológicas com a embebição são consideradas ortodoxas, como é o caso do crambe (OLIVA, 2010). Nesse sentido, Garcia et al. (2004) ressaltam que a secagem de sementes, visando reduzir os elevados teores de água durante a colheita, além de contribuir para a preservação da qualidade fisiológica durante o armazenamento, possibilita a antecipação da colheita evitando perdas de natureza diversa durante o processo produtivo.

O peso da matéria seca das sementes, que, aos 14 dias após a floração, era de 3,97 mg por semente, aumentou acentuadamente até atingir $6,10 \mathrm{mg}$ por semente aos 26 dias após a floração (Figura 1) que correspondeu a 1302,15 GD. Esses valores mostram incremento de 53,65\% no peso da matéria seca das sementes da primeira colheita até o ponto de máximo. A partir de 26 dias após a floração, houve decréscimos no conteúdo de matéria seca até atingir 4,22 mg por semente, período em que ocorreu a última época de colheita (38 dias após a floração). Possivelmente, esse resultado está associado às perdas pela respiração das sementes em decorrência das condições climáticas observadas durante a condução do experimento (DAVID et al., 2003).

Diversos estudos (DAVID et al., 2003; SOUSA et al., 2011) avaliando a maturação de sementes de diversas espécies apontam o ponto de máximo conteúdo de matéria seca como o melhor e mais seguro indicativo de que as sementes atingiram a maturidade fisiológica. Entretanto, Ellis e Pieta Filho (1992) consideram necessário que se utilize o termo maturidade fisiológica para o ponto de máxima qualidade fisiológica, denominando o ponto de máximo acúmulo de matéria seca como maturidade de massa, visto que, para algumas espécies, o máximo de qualidade fisiológica ocorre após a máxima massa da matéria seca.

Aos 14 dias após a floração, as sementes apresentavam-se com aproximadamente 5,0 g na massa mil sementes (Figura 1). A partir desse período, esses valores aumentaram até atingir aos 28 dias após a floração (próximo à quarta colheita) $7,35 \mathrm{~g}$, época em que ocorreu o máximo valor na massa de mil sementes, próximo ao período de maior acúmulo de matéria seca (26 dias após a floração). Houve um acréscimo de $47 \%$ na massa de mil sementes da primeira colheita até o ponto máximo que correspondeu a 1332,05 graus dia. A partir desse período, verificou-se um decréscimo que prosseguiu até a última colheita, sendo esses valores decrescentes até atingirem 6,0 g aos 38 dias após a floração. 
Figura 1. Matéria seca e massa de mil sementes de crambe, cultivar FMS Brilhante, em função da época de colheita.

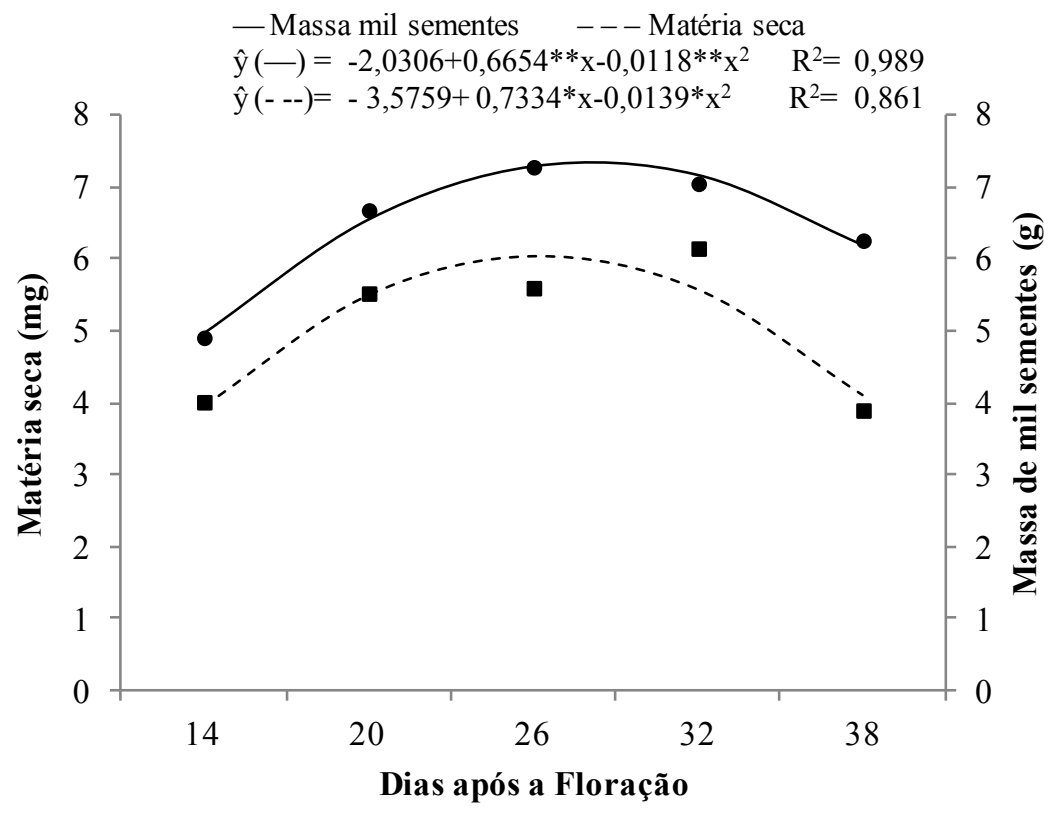

Fonte: Elaboração dos autores.

Observa-se por meio da Figura 2 que as sementes apresentavam aproximadamente $76 \%$ de germinação já na primeira época de colheita (14 dias após a floração). No entanto, a partir desse período, verificou-se uma redução constante na porcentagem de germinação até a última colheita, atingindo valores médios de $47 \%$. Esses resultados demonstram uma redução de aproximadamente $38 \%$ na germinação da primeira até a quinta época de colheita.

Os baixos valores verificados na porcentagem de germinação, à medida que se colhia as sementes, podem estar associados ao hábito de florescimento indeterminado apresentado pela cultura do crambe e à dormência pós-colheita presente em suas sementes. Conforme observado por Costa et al. (2011) e Oliva (2010) a desuniformidade presente nos racemos, possivelmente, contribuiu com a dormência em diferentes graus das sementes que compõe as colheitas. Além dos fatores genéticos, o ambiente tem grande influência na implementação da dormência durante o desenvolvimento da semente, tais como o comprimento do dia, a qualidade da luz, a nutrição mineral, a competição, a temperatura, o estádio fisiológico da planta e a posição da semente na planta mãe (HILHORST, 2007). 
Figura 2. Germinação de sementes, emergência e índice de velocidade de emergência de plântulas de crambe, cultivar FMS Brilhante, em função da época de colheita.

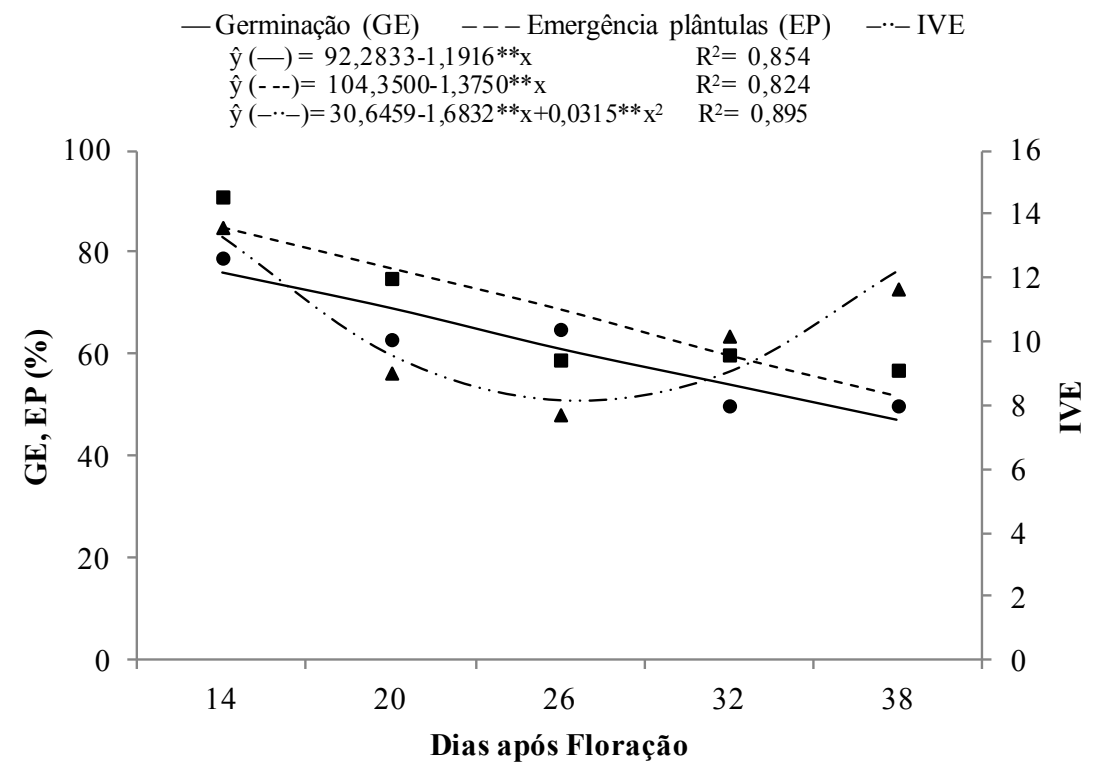

Fonte: Elaboração dos autores.

A máxima porcentagem de germinação ocorreu aos 14 dias após a floração (Figura 2), ou seja, antes da maturidade fisiológica, com base no máximo acúmulo de matéria seca das sementes (Figura 1). Esse resultado esta de acordo com David et al. (2003) que observaram máxima germinação antes do ponto de maturidade fisiológica, com base no acúmulo de matéria seca das sementes. A máxima porcentagem de germinação nesse período pode estar associada ao fato de que estas sementes ainda não haviam formado o mecanismo de dormência, visto que a dormência se instala durante a maturação das sementes (dormência primária) ou logo após a dispersão, induzida por condições de estresse.

Para espécies de crescimento indeterminado, o florescimento e, consequentemente, a formação das sementes, ocorre por um extenso período, o que evidencia os efeitos da maturação na qualidade fisiológica das sementes. Assim, sementes em vários estágios de desenvolvimento estão presentes na planta de maneira simultânea (FONTANA et al., 1988). Cada racemo ou semente de uma mesma planta de crambe pode ser formado em condições edafoclimáticas diferentes. Portanto, sementes colhidas em diferentes racemos ou posições no racemo são afetadas pelas condições ambientais vigentes antes e durante a sua formação, podendo apresentar germinação e vigor distintos (LUCENA et al., 2006).

É importante salientar que sementes que apresentam algum grau de dormência podem vir a germinar durante o teste de germinação com atraso em relação àquelas sementes que não apresentam nenhuma dormência. Segundo Hilhorst (2007), diferenças na velocidade de germinação podem ser indicadores de dormência, sendo que o tempo necessário para germinação pode variar com o grau da dormência.

Os resultados obtidos no teste de emergência de plântulas evidenciam que, já na primeira época de colheita, as sementes apresentavam-se vigorosas, com aproximadamente $85 \%$ de emergência (Figura 2) que representou 1111,1 graus dia. A partir do período de máxima emergência (14 dias após a floração), os valores decresceram de maneira linear 
e constante, nas demais colheitas realizadas aos 20 , 26, 32 e 38 dias após a floração, sendo observados valores de 76, 69, 60, 52\% de plântulas normais emergidas, respectivamente. Tal fato provavelmente esta relacionado à desuniformidade de maturação na cultura do crambe, em que o maior número de sementes ainda não totalmente formadas pode ter contribuído para os resultados encontrados.

$\mathrm{O}$ vigor das sementes, com base no índice de velocidade de emergência, apresentava já na primeira época de colheita índices expressivos de 13,3, sendo considerado como ponto de máximo (Figura 2). Maiores índices indicam que as sementes germinaram mais rapidamente e de maneira uniforme, sendo, portanto, mais vigorosas. Entretanto, a partir da primeira colheita, houve decréscimos na velocidade de germinação das sementes até a terceira colheita, com índice de 8,16 aos 27 dias após a floração, sendo esse valor considerado com ponto de mínimo. Essa queda do vigor com base nos valores do teste índice de velocidade de emergência, no período compreendido entre a primeira até a terceira colheita, foi de aproximadamente $63 \%$.

A partir da terceira colheita, ou seja, aos 28 dias após a floração, houve uma retomada na curva, na qual os resultados foram se elevando, e aos 38 dias após a floração, período que ocorreu a quinta época de colheita, as sementes apresentavam-se com valores próximos aos verificados no ponto de máximo $(12,17)$.

Momoh, Zhou e Kristiansson (2002), trabalhando com sementes de canola (Brassica napus L.), relataram que não apenas a germinação final deve ser considerada, mas também a velocidade e a distribuição da germinação. Em seu estudo, as sementes com menor velocidade de germinação apresentaram maior potencial em desenvolver dormência secundária.

A melhor época para realizar a colheita de sementes de crambe, cultivar FMS Brilhante, com maior qualidade fisiológica (maior germinação e vigor) ocorre no período de 14 a 26 dias após a floração, que representa uma soma térmica de 1111,1 a 1302,15 graus dia.

\section{Agradecimentos}

Agradeço à Fundação de Amparo à Pesquisa do Estado de Minas Gerais(FAPEMIG) è̀ Universidade Estadual de Montes Claros (UNIMONTES), pelo apoio financeiro e técnico para o desenvolvimento desta pesquisa.

\section{Referências}

BRASIL. Ministério da Agricultura, Pecuária e Abastecimento. Regras para análise de sementes. Brasília: SDA. Mapa/ACS. D.O.U., 01 out. 2009. 399 p.

CARLSON, A. S.; CLAYTON, D.; SALENTIJN, E.; TOONEN, M. Oil crop platforms for industrial uses. Newbury: Outputs from the EPOBIO project, 2007. Disponível em: <http://epobio.net/ pdfs/0704OilCropsReport.pdf $>$. Acesso em: 10 abr. 2012.

COSTA, L. M.; RESENDE, O.; GONÇALVES, D. N.; SOUSA, K. A. Coeficiente de difusão efetivo para a secagem de sementes de crambe (Crambe abyssinica). Revista Brasileira de Engenharia Agrícola e Ambiental, Campina Grande, v. 15, n. 10, p. 1089-1096, 2011.

DAVID, A. M. S. S.; ARAÚJO, E. F.; MIRANDA, G. V.; DIAS, D. C. F. S.; GALVÃO, J. C. C.; CARNEIRO, V. Maturação de sementes de milho-pipoca. Revista Brasileira de Milho e Sorgo, Sete Lagoas, v. 2, n. 3, p. 121-131, 2003.

ELLIS, R. H.; PIETA FILHO, C. Seed development and cereal seed longevity. Seed Science Research, Zurich, n. 2, p. 9-15, 1992.

FARIA JÚNIOR, C. A. Adaptabilidade da Cultura do Crambe no Estado de Mato Grosso. 2013. Dissertação (Mestrado em Ambiente e Sistemas de Produção Agrícola) - Universidade do Estado de Mato Grosso, Tangará da Serra.

FONTANA, F.; LAZZERI, L.; MALAGUTI, L.; GALLETTI, S. Agronomic characterization of some Crambe abyssinica genotypes in a locality of the po valley. European Journal of Agronomy, Amsterdam, v. 9, n. 2, p. 117-126, 1998. 
FUNDAÇÃO MATO GROSSO DO SUL. Culturas para biodiesel. Crambe: Maracajú, 2007. Disponível em: $<$ http://www.fundacaoms.com.br $>$. Acesso em: 15 maio 2009.

GARCIA, D. C.; BARROS, A. C. S. A.; PESKE, S. T. P.; MENEZES, N. L. A secagem de sementes. Ciência Rural, Santa Maria, v. 34, n. 2, p. 603-608, 2004.

HILHORST, H. W. M. Definitions and hypotheses of seed dormancy. In: BRADFORD, K. J.; NONOGAKI, H. Seed development, dormancy and germination. Oxford: Blackwell, 2007. p. 50-71.

KNIGHTS, S. E. Crambe: a North Dakota case study. Kingston: Rural Industries Research and Development Corporation, 2002. (RIRDC Publication No W02/005, RIRDC Project No TA001-55). Disponível em: $<$ http:// www.rirdc.gov.au/reports/NPP/02-005.pdf>. Acesso em: 16 jan. 2012.

LUCENA, A. M. A.; SEVERINO, L. S.; FREIRE, M. A. O.; COSTA, F. X.; BELTRÃO, N. E. M. Umidade e peso seco da semente e do fruto de mamona BRS Paraguaçu colhidos em três estádios de maturação. In: CONGRESSO BRASILEIRO DE MAMONA, 2., 2006, Campina Grande. Anais... Campina Grande: Embrapa Algodão, 2006. CD-ROM.
MAGUIRE, J. D. Speed of germination-aid in selection and evaluation for seedling emergence and vigor. Crop Science, Madison, v. 2, n. 1 p. 176-177, 1962.

MOMOH, E. J. J.; ZHOU, W. J.; KRISTIANSSON, B. Variation in the development of secondary dormancy in oilseed rape genotypes under conditions of stress. Weed Research, Oxford, v. 42, n. 6, p. 446-455, 2002.

OLIVA, A. C. E. de. Qualidade de sementes de crambe submetidas a métodos de secagem e períodos de armazenamento. 2010. Dissertação (Mestrado em Agronomia) - Faculdade de Ciências Agronômicas da UNESP, Botucatu.

SOUSA, T. V.; ALKIMIM, E. R.; DAVID, A. M. S. S.; SÁ, J. R.; PEREIRA, G. A.; AMARO, H. T. R.; MOTA, W. F. Época de colheita e qualidade fisiológica de sementes de coentro produzidas no norte de Minas Gerais. Revista Brasileira de Plantas Medicinais, Botucatu, v. 13, p. 591-597, 2011. Especial. 